\title{
RELATIONS AMONG MECHANICAL PROPERTIES, COLLAGEN FIBERS, AND CALCIFICATION IN ADULT HUMAN CORTICAL BONE*广
}

\author{
RAÚL VINCENTELLI \\ Facultad de Odontología, Cátedra de Histologia y Embriologia. Universidad Central de \\ Venezuela. Caracas, Venezuela \\ and \\ F. GAYNOR EVANS \\ Department of Anatomy (Medical School) and Biomechanics Department (Highway Safety \\ Research Institute). The University of Michigan. Ann Arbor, Michigan. U.S.A.
}

\begin{abstract}
The relations of ulimate tensile stress and strain and modulus of elasticity to collagen fiber orientration and degree of calcification were studied in thirty-six standardized specimens of unembalmed cortical bone from adult human tibias. Highly significant positive correlations were found between tensile stress and strain and pereentage of dark osteons in the break area. A similor correlation occurred borween tensile strain and dark osteons plus fragments. Tensile stress and strain had highly significant negative correlations with light osteons and their fragments but a lower negative correlation with intermediate osteons. Significant negative correlations were found between the intermediate rodiolucent and the marked radjolucent osteons and teasile stress and strain, respectively. Partialing out interstitial lamellae and intermediete radiolucent areas revealed significant positive and negative correlations between tensile stress and dark and bight osteons, respectively. No significant correlations occurred between modulus of elasticity and any of the histological variables.
\end{abstract}

\section{INTRODUCTION}

Although the present investigation is a supplement to our previous one (Evans and Vincentelli, 1969) the two studies are not directly comparable. In the first study, based on embalmed material from old men, the only histological variable considered was collagen fiber orientation while in the present study, using unembalmed material from young as well as old men, the degree of calcification in addition to collagen fiber orientation was included.

A close relationship between bone hardness and the amount of mineralization (as revealed by microradiography) was demonstrated several years ago by Carlström (1954) and later elaborated on by Amprino (1958). According to Amprino and Engström (1952) the degree of mineralization in Haversian bone as compared with fully calcified primary bone varies from about 70 per cent in newly formed osteons to about 95 per cent in older osteons. These figures were later confirmed, using biochemical methods, by Strandh (1960).

Currey (1959) reported a strong negative correlation between the tensile strength of beef bone and the "percentage of "Haversian System' type bone in it". This correlation was attributed principally to the reduction in the total amount of calcium in the bone produced by the lower degree of mineralization in the osteons.

Because the material used in our earlier study was not suitable for microradiographic analysis the present study was undertaken in order to determine if the previously reported correlations between mechanical properties of bone and collagen fiber orientation would

* Received 9 November 1970.

+This research was supported (in part) by Research Grant AM 03865-12 from the National Institutes of Health. USPHS. 
be affected when the degree of calcification was also included as a variable.

\section{MATERIALS AND METHODS}

The present investigation is based on 36 specimens of a standardized size and shape machined from the diaphyseal cortex of unembalmed tibias of four white men ranging from 23 to 74 years of age. The long axis of the specimen coincided with that of the shaft of the bone. The ultimate tensile strength (UTS), per cent elongation (tensile strain), and modulus of elasticity ( $E$ ) of the specimens were determined by the same methods used by Evans and Lebow (1951).

After the mechanical properties of the specimens had been determined, they were embedded in polystyrene and cross-sections taken as close to the fracture site as possible. The cross-sections were ground to a thickness of $100 \mu$ and a microradiograph taken of each one. Later the sections were ground to a thickness of $70 \mu$, decalcified, mounted, and photomicrographs taken under polarized light with a Zeiss photomicroscope.

Osteons and their fragments were classified as light osteons (LO) and fragments (LF), intermediate osteons (1O) and fragments (IF), dark osteons (DO) and fragments (DF), according to their appearance in the polarized light photomicrograph (Fig. 1). In the light osteons the majority of the collagen fibers spiral around the long axis of the osteon at an angle almost perpendicular to it. In the dark osteons the orientation of the majority of the fibers is more nearly parallel to the long axis of the osteon. In the intermediate osteons, collagen fibers with both types of orientation are more evenly distributed in the osteon.

On the basis of their appearance in the microradiographs the osteons and their fragments were classified into slightly (SR), intermediate (IR), and markedly radiolucent (MR) groups (Fig. 2). The degree of calcification was least in the MR group, greater in the SR group, and greatest in the older osteons and their fragments and in the inter- stitial lamellae. Because of their uniform radioopacity the older osteons, fragments and interstitial lamellae were not considered as separate variables.

The percentage of the cross-sectional area formed by the different histological variables was determined with respect to the original break area and the corrected break area. The original break area (OBA) was represented by the intact cross-section, the corrected break area (CBA) by the intact section minus the area of the Haversian canals, Volkmann's canals, and resorption spaces. For further details of the analysis see our earlier publication (loc. cit).

The corrected break area was the one used in the final analysis of the histological composition of the cross-sections since, except for the lacunae and the canaliculi, it represented the area of bone subjected to stress during a mechanical property test. The area of the lacunae and the canaliculi was not considered to be significant because, according to Frost (1960), their combined volume in a vascular-free volume of cortical bone from human long bones is less than 3 per cent.

All histological analysis of the cross-sections was made by the same person in order to reduce the amount of error in the technique.

Correlation coefficients between the mechanical properties of the specimens and the percentage of the original and the corrected break areas formed by each of the histological variables were calculated in The University of Michigan Computing Center.

\section{RESULTS}

The differences between the correlation coefficients computed for the original break area and the corrected break area were so small that, except for the data in Table 6, only correlations for the corrected break area will be considered.

When the relations between the mechanical properties of the specimens and the orientation of the collagen fibers in the various histological components of the section (Table 1) 
Table 1. Correlation coefficients between some mechanical properties of wet, unembolmed cortical bone from tibins of adult men and different types of osteons. See text for explanation of osteon types

\begin{tabular}{lccc}
\hline & $\begin{array}{r}\text { Modulus of } \\
\text { elasticity }\end{array}$ & $\begin{array}{c}\text { Ultimate tensile } \\
\text { strength }\end{array}$ & $\begin{array}{c}\text { Per cent } \\
\text { elongation }\end{array}$ \\
\hline Light osteons & -0.228 & $-0.487 \dagger$ & $-0.738^{*}$ \\
Intermediate osteons & -0.010 & -0.291 & -0.031 \\
Dark osteons & 0.297 & $0.443 \dagger$ & $0.530^{*}$ \\
\hline${ }^{*}=0.001$. & & & \\
$\dagger=0.01$. & & &
\end{tabular}

were analyzed, a positive correlation was found between the dark osteons and the ultimate tensile strength and the per cent elongation of the specimens. The correlation with tensile strength was significant at the 0.01 level and that with elongation at the 0.001 level. Light osteons had negative correlations, at the same significance levels, with ultimate tensile strength and per cent elongation. No significant correlations were found between the intermediate type osteons and any mechanical property investigated.

Combining the different types of osteons with their fragments produced some changes in the correlations (Table 2). The dark group of osteons and their fragments had a ments had a negative correlation, at the 0.05 significance level, with ultimate tensile strength.

Significant correlations were also found between some of the mechanical properties of the specimens and different degrees of calcification or radiolucency of the sections (Table 3). Ultimate tensile strength had a negative correlation with the intermediate radiolucent group and per cent elongation a negative correlation with the marked radiolucent group. Both correlations were significant at the 0.05 level.

The correlation coefficients between the mechanical properties of the specimens and the per cent of the original break area formed

Table 2. Correlation coefficients between some mechnnical properties of wet, unembaimed cortical bone from tibias of adult men and different types of osteons plus their fragments

\begin{tabular}{lccc}
\hline & $\begin{array}{r}\text { Modulus of } \\
\text { elasticity }\end{array}$ & $\begin{array}{c}\text { Ulimate tensile } \\
\text { strength }\end{array}$ & $\begin{array}{c}\text { Per cent } \\
\text { elongation }\end{array}$ \\
\hline Light group & -0.300 & $-0.531^{*}$ & $-0.678^{*}$ \\
Intermediate group & -0.094 & $-0.399^{\dagger}$ & -0.026 \\
Dark group & 0.180 & 0.298 & $0.382 \dagger$ \\
\hline
\end{tabular}

$*=0.001$.

$\dagger=0.05$.

positive correlation, at the 0.05 significance level, with per cent elongation but there was no positive correlation with any other mechanical property. The light group had a negative correlation, at the 0.001 significance level, with ultimate tensile strength and the per cent elongation. In contrast to the situation when the osteons were considered alone, the intermediate group of osteons plus frag- by the spaces were -0.385 for modulus of elasticity, -0.702 for ultimate tensile strength, and -0.515 for per cent elongation. The correlation between spaces and the modulus of elasticity was significant at the 0.05 level and that between spaces and the ultimate tensile strength and the per cent elongation at the 0.001 level.

In order to investigate the way in which 
Tabie 3. Correlation coefficients between some mechanical properties of wet, unembalmed cortical bone from tibias of adult men and different radiolucent areas. See text for explanation of radiolucent areas

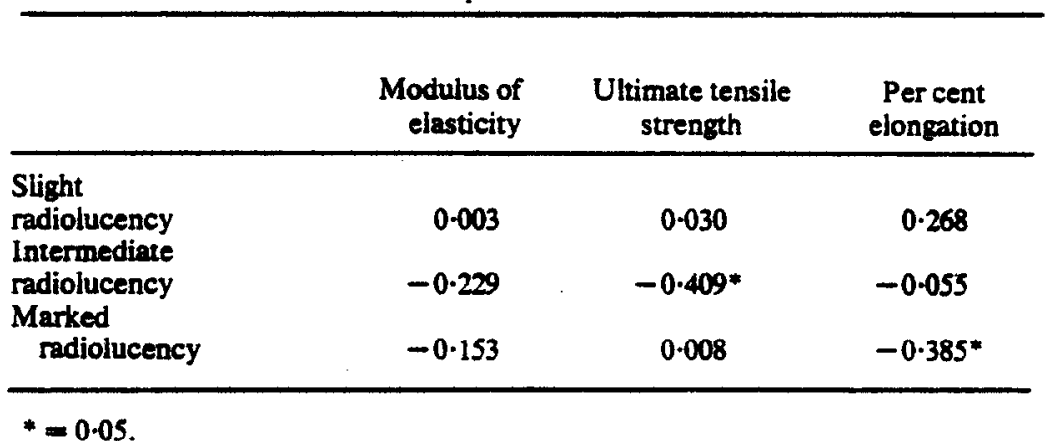

variations in the degree of calcification would affect the correlations between collagen fiber orientation and mechanical properties the microradiographic variable (the intermediate radiolucent group) showing the highest correlation with mechanical properties was partialed out. Partial correlation coefficients were then computed between the different types of osteons, classified on the basis of their appearance in polarized light, and the ultimate tensile strength and the per cent elongation of the specimens (Tables 4 and 5). In addition, the interstitial lameliae were partialed out because they also form a part of the cross-section of the specimen. Comparison of the data in Tables 1 and 2 with those in Tables 4 and 5 show that correlations between mechanical properties and histological components still persist although the significance level of the correlation is lower in some instances.

Multiple correlations, using tensile strength or per cent elongation as the dependent variables and all the histological and microradiographic components as the independent variables, were also computed in order to estimate how accurately the mechanical properties of bone can be predicted on the basis of its collagen fiber orientation and degree of mineralization. It was found (Table 6) that ultimate tensile strength and per cent elongation each had a positive correlation, at the 0.001 significance level, with the percentage of the corrected break area and of the original break area formed by the various independent variables. However, the magnitude of the correlation between ultimate tensile strength and the histological and microradiographic variables was greater with the original break area than with the corrected break area.

\section{Discussion}

In the present study the correlations found between ultimate tensile strength or per cent elongation of the specimens and the percentage of the break area formed by light or dark osteons or by light or dark osteons plus their fragments are much higher than for the embalmed specimens used in our previous study (loc. cit.). However, no significant correlations between the modulus of elasticity and the percentage of the break area formed by light or dark osteons or by light or dark osteons plus their fragments were found in the present investigation. This is probably the result of the smaller sample size of the unembalmed material, the actual values for some of the coefficients being only a little different from those for the embalmed specimens. Shearing test data were not available for eleven of the unembalmed specimens so this mechanical property was not included in the present study.

The discrepancies between some of the results of this study and those of our earlier 
Table 4. Partial correlation coeficients between uhtimate tensile strength of wet, unembalmed cortical bone from tibias of aduit men and different osteon types plus fragments when the intermediate radiolucent areas

(IR) and the interstitial lamellac (IL) are partialed out

\begin{tabular}{llc}
\hline \multicolumn{1}{c}{$\begin{array}{c}\text { Variables } \\
\text { correlated }\end{array}$} & $\begin{array}{c}\text { Variables } \\
\text { partialed out }\end{array}$ & $\begin{array}{c}\text { Parial } \\
\text { correlation }\end{array}$ \\
\hline $\begin{array}{ll}\text { Ultimate tensile strength with: } \\
\text { Light osteons }\end{array}$ & IR & $-0.4159 \dagger$ \\
& IR. IL & $-0.3858 \dagger$ \\
Dark osteons & IR & $0.4088 \dagger$ \\
& IR. IL & $0.5074^{*}$ \\
Light osteons & IR & $-0.4971^{*}$ \\
plus fragments & IR. IL & $-0.4530^{*}$ \\
Dark osteons & IR & 0.2590 \\
plus fragments & IR. IL & $0.4811^{*}$ \\
\hline$*=0.01$. & & \\
$\dagger=0.05$. & &
\end{tabular}

Table 5. Partial correlation coefficients between the per cent elongation of wet, unembalmed cortical bone from tibias of adult men and different osteon types plus their fragments when the intermediate radiolucent areas (IR) and the interstitial lamellae (IL) are partialed out.

\begin{tabular}{llr}
\hline $\begin{array}{c}\text { Variables } \\
\text { correlated }\end{array}$ & $\begin{array}{c}\text { Variables } \\
\text { partialed out }\end{array}$ & $\begin{array}{c}\text { Partial } \\
\text { correlation }\end{array}$ \\
\hline $\begin{array}{ll}\text { Per cent elongation with: } \\
\text { Light osteons }\end{array}$ & IR & $-0.7510^{*}$ \\
Dark osteons & IR. IL & $-0.7453^{*}$ \\
& IR & $0.5269^{*}$ \\
Light osteons & IR. IL & $0.5659^{*}$ \\
plus fragments & IR & $-0.6806^{*}$ \\
Dark osteons & IR, IL & $-0.6741^{*}$ \\
plus fragments & IR & $0.3764 \ddagger$ \\
\hline$=0.001$. & IR, IL & $0.4895 \dagger$ \\
\hline$\neq=0.01$. & & \\
$\ddagger=0.05$. & &
\end{tabular}

investigation are probably due to (1) differences in the mechanical properties of embalmed and unembalmed bone, (2) differences in the ages of the subjects from which the test specimens were obtained, and (3) the fact that only tibial specimens were used in the present study while in our previous one, data from femoral, tibial, and fibuiar specimens were combined. It is known that embalming increases the tensile strength, bending modulus, and hardness of bone, but reduces its compressive strength (Evans, in preparation). There are also age differences in the mechanical properties (Melick and Miller, 1966; Yamada, 1970) and microscopic structure of bone (Amprino and Bairati, 1936; Jowsey, 1960).

The predominant orientation of collagen fibers within an osteon has been attributed to the influence of mechanical factors at the moment of osteon formation (Olivo, 1937; Olivo et al. 1937). There also seems to exist some correlation between collagen fiber orientation and the age at which osteon formation occurs. Amprino and Bairati (loc. cit.), found a predominance of osteons with 
Table 6. Multiple correlation coefficients between either the ultimate tensile strength (UTS) or the per cent elongation of wet. unembalmed cortical bone from tibias of adult men and all histologic and microradiographic variables before $(R)$ and after $\left(\tilde{R}_{e}\right)$ correcting for sample size

\begin{tabular}{|c|c|c|c|c|c|}
\hline $\begin{array}{l}\text { Dependent } \\
\text { variable }\end{array}$ & $\begin{array}{l}\text { lindependent } \\
\text { variables }\end{array}$ & Break area & $R$ & $\bar{R}_{\mathrm{c}}$ & $\begin{array}{l}\text { Standard } \\
\text { error of } \bar{R}_{c}\end{array}$ \\
\hline UTS & $\begin{array}{l}\text { LF, DF, LO, IO. } \\
\text { DO, SR, IR, MR }\end{array}$ & $\mathrm{CBA}$ & 0.688 & $0.564^{*}$ & $0: 131$ \\
\hline UTS & $\begin{array}{l}\text { LF, IF, DF, LO, } \\
\text { IO, DO,IL, SP, } \\
\text { SR, IR, MR }\end{array}$ & OBA & 0.845 & $0.764^{*}$ & 0.085 \\
\hline \% Elongation & $\begin{array}{l}\text { LF, DF, LO, IO } \\
\text { DO,SR,IR, MR }\end{array}$ & $\mathrm{CBA}$ & 0.824 & $0.765^{*}$ & 0.079 \\
\hline \% Elongation & $\begin{array}{l}\text { LF, IF, DF, LO } \\
\text { IO, DO, SP, SR, } \\
\text { IR. MR }\end{array}$ & OBA & 0.838 & $0.764^{*}$ & 0.083 \\
\hline
\end{tabular}

$*=0.001$.

$\mathrm{CBA}=$ corrected break area. $\mathrm{OBA}=$ original break area.

$L F=$ light fragments. $D F=$ dark fragments. $I F=$ intermediate fragments. $L O=$ light osteons. 10 = intermediate osteons, $\mathrm{DO}=$ dark osteons. $\mathrm{SR}=$ slight radiolucency. $\mathrm{IR}=$ intermediate radiolucency, $M R=$ marked radiolucency. $S P=$ spaces, IL = interstitial lamellac.

steeply spiraling collagen fibers in younger individuals, while osteons with collagen fibers running in a circular or a low angle of spiral were more frequent in older people. A correlation between bone age and collagen fiber orientation within osteons has also been reported by Smith (1960) who attributes it to changes in fiber orientation taking place after calcification during aging of the osteon. Thus, his Type I osteon (our light type) would, with time, become a Type III osteon (our dark type).

Collagen fibers have a definite orientation within individual lamellae during bone matrix formation before calcification occurs. Small hydroxyapatite crystals appear not only between and on, but even within individual fibrils (Cooper et al. 1966). A change in collagen fiber orientation after calcification, as suggested by Smith, implies a total rearrangement of the crystallites within an osteon. The mechanism responsible for such a change is difficult to imagine.

Our study of polarized light photomicrographs does not agree with Smith's explanation for collagen fiber orientation. When we compared individual osteons with their corresponding images in the microradiographs we found that newly formed osteons, i.e. the more radiolucent ones, tended to be of the light type in specimens from older individuals while in specimens from younger subjects most of the osteons were of the dark type. Unfortunately, we do not have a large enough number of subjects to permit a statistical analysis to determine whether a correlation between osteon type and age really exists.

Our classification of osteons according to their appearance in the polarized light photomicrographs is based on the number of light appearing lamellae. In our dark type of osteon most or practically all of the lamellae are dark while in our light type of osteon there is a regular or almost regular alternation of light and dark lamellae throughout the osteon. Our light type of osteon corresponds to Smith's Type I osteon while our dark type is more like his Type III osteon.

Our light and dark types of osteons are equivalent to the two types of osteons described by Ascenzi and Bonucci (1964) in their study of the tensile strength of individual osteons and to their Type 2 and Type 3 osteons in their later publication (1968) on the compressive strength of individual osteons. We found very few osteons corres- 
ponding to their Type 1. They were included in our light group. The osteons we classified as intermediate had neither an even distribution of akernating light and dark lamellae nor a very marked predominance of dark lamellae.

There is, of necessity, a subjective factor in the determination of the limits within which an osteon is classified as intermediate instead of light or dark. The actual distribution of light lamellae within an intermediate osteon was not considered in our classification. Consequently we may have overlooked the existence of possible subgroups with different mechanical properties as discussed by Gebhardt (1905). We believe that our light and dark groups of osteons are more distinct than our intermediate group. Thus, we feel that the conclusions based on them are more valid than those based on the intermediate group.

The high positive correlation between the ultimate tensile strength of our specimens and the percentage of their break area formed by dark osteons is what one would expect from the studies of Ascenzi and Bonucci $(1964,1967)$. These investigators reported that the ultimate tensile strength of individual osteons with a marked longitudinal arrangement of their collagen fibers in successive lamellae (which makes them appear dark in polarized light) is greater than in osteons whose collagen fibers change through an angle of $90^{\circ}$ in successive lamellae. Osteons with different degrees of calcification but the same collagen fiber orientation showed no significant variation in tensile strength. In contrast to Ascenzi and Bonucci who reported that dark osteons also had a higher modulus of elasticity than other types we found no significant correlations between the modulus of our specimens and the percentage of the break area formed by dark, light, or intermediate osteons.

Osteons of long bones generally have their long axes coinciding with that of the shaft of the bone. The same is true of the majority of the collagen fiber bundles in the osteons that appear dark in polarized light. Consequently, these osteons are in a better mechanical position to resist tensile stress and strain in the direction of the shaft of the bone than are osteons whose collagen fiber bundles are predominantly oriented at a large angle to the long axis of the osteon and the bone. Thus, the greater the number of dark osteons in a given volume of bone the higher is its tensile strength. Conversely, the greater the number of light or intermediate osteons in the bone the lower is its tensile strength. These interpretations are supported by the high negative correlations we found between tensile strength and the percentage of the break area formed by light and by intermediate osteons.

The probable reason that no significant positive correlation was found between tensile strength and dark osteons plus their fragments is that the fragments are only parts of osteons, and consequently are not as mechanically efficient in resisting tensile stress and strain as are intact osteons.

The low correlation we found between the tensile strength of our specimens and the percentage of the break area formed by the markedly radiolucent osteons (MR) is probably due to the fact that they constituted only $1.38 \pm 1.74$ per cent of the total cross-sectional area. The slightly radiolucent group of osteons (SR), on the other hand, while forming $36 \cdot 6 \pm$ 14.1 per cent of the cross-sectional area. appeared only slightly different from the fully calcified background. This may account for their lack of correlation with the mechanical properties of the specimens. The intermediate radiolucent osteons (IR) formed 10.7 \pm 8.54 per cent of the cross-sectional area. Their low degree of calcification probably explains their negative correlation with ultimate tensile strength of the specimens.

\section{SUMMARY AND CONCLUSIONS}

1. The ultimate tensile strength, per cent elongation, and modulus of elasticity were determined for 36 standardized specimens of 
unembalmed cortical bone from tibias of four men.

2. Cross-sections, taken as close to the fracture site as possible, were studied by polarized light microscopy and by microradiography.

3. Osteons and their fragments were classified as light, intermediate, or dark on the basis of their appearance in polarized light.

4. According to their radiolucency osteons and their fragments were categorized as slight, intermediate, or marked radiolucent.

5. Ultimate tensile strength and per cent elongation had a high positive correlation with the per cent of the break area formed by dark osteons. Per cent elongation also had a positive correlation with the dark group of osteons plus their fragments.

6. Ultimate tensile strength and per cent elongation had high negative correlations with light osteons, and the light group of osteons plus their fragments and a lower negative correlation with the intermediate group of osteons plus fragments.

7. Tensile strength and per cent elongation both had negative correlations, at the 0.05 significance level, with the group of osteons and their fragments showing intermediate radiolucency and marked radiolucency, respectively.

8. After the interstitial lamellae and the intermediate radiolucent areas were partialed out ultimate tensile strength had a positive partial correlation, with (a) the dark osteons and (b) the group of dark osteons plus their fragments. Equally high negative partial correlations were found between tensile strength and (a) the light osteons and (b) the light group of osteons plus their fragments.

9. Highly significant multiple correlations before and after correcting for sample size were found between the various histological variables in the original and corrected break areas and ultimate tensile strength and per cent elongation, respectively.

10. No significant correlations were found between modulus of elasticity and any of the histological or microradiographic variables involved in the study.

Acknowledgements - The authors wish to express their thanks and appreciation to Miss Esther Schacfier of The University of Michigan Statistical Research Laboratory and Mrs. Elizabeth Rossi of the Dental Education Office, Universidad Central de Venezuela, for their advice and assistance with the statistical analysis involved in this research.

\section{REFERENCES}

Amprino, R. (1958) Investigations on some physical properties of bone tissue. Acta Anat. 34, 161-186.

Amprino, R and Bairati, A. (1936) Processi di ricostruzione e di riassorbimento nella sostanza compatta delle ossa dell'uomo. Z. Zellforsch. mikrosk. 24, 439511.

Amprino, R. and Engstrom. A. (1952) Studies on $x$ ray absorption and diffraction of bone tissue. Acta Anat. 15, 1-22.

Ascenzi, A. and Bonucci, E. (1964) The ultimate tensile strength of single osteons. Acta Arat. 58, 160-183.

Ascenzi. A. and Bonucci, E. (1967) The tensile properties of single osteons. Anat. Rec. 158, 375-386.

Ascenzi. A. and Bonucci, E. (1968) The compressive properties of single osteons. Anat. Rec. 161, 377-392.

Cariström. D. (1954) Micro-hardness measurements on single Haversian systems in bone. Experientia 10 , $171-173$.

Cooper, R. R., Milgram. J. W. and Robinson, R. A. (1966) Morphology of the osteon. J. Bone Jt Surg. 48A. 1239-1271.

Currey, J. D. (1959) Differences in the tensile strength of bone of different histological types. J. Anat. 93, 87-95.

Evans, F. G. The Mechanical Properties of Bone. Williams and Wilkins, Baltimore (in preparation).

Evans, F. G. and Lebow, M. (1951) Regional differences in some of the physical properties of the human femur. J. appl. Phys. 3, 563-572.

Evans, F. G. and Vincentelli, R. (1969) Relation of collagen fiber orientation to some mechanical properties of human cortical bone. J. Biomechanics 2,63-71.

Frost, H. M. (1960) Measurement of osteocytes per unit volume and volume components of osteocytes and canaliculae in man. Henry Ford Hosp. med. Bull. 8, 208-211.

Gebhardt, W. (1905) Uber funktionell wichtige Anordnungsweisen der feineren und grösseren Bauelemente des Wirbeltierknochens. II. Spezieller Teil. Arch. EntwMech. Org. 20, 187-322.

Jowsey, J. (1960) Age changes in human bone. Clin. Orthop. 17, 210-218.

Melick. R. A. and Miller, D. R. (1966) Variations of tensile strength of human cortical bone with age. Clin. Sci. 30, 243-248.

Olivo, O. M. (1937) Rapport entre la structure et la fonction dans les osteons. C. r. Ass. Anat. 32. 334-346.

Olivo, O. M.. Maj. G. and Toajari, E. (1937) Sul signif- 
cato delia minuta struttura del tessuto osseo compatto. Strandh, J. (1960) Microchemical studies on single Boll. Sci. med. 109. 369-394.

Haverisan systems. Expl. Cell Res. 19,515-530.

Smith, J. W. (1960) The arrangement of collagen fibres Yamada. H. (1970) Strength of Biological Materials. in human secondary osteones. J. Bone Jt Surg. 42B, Willams and Wilkins, Baltimore. 588-605. 